\title{
PENGARUH SUMBER AIR BERSIH, JAMBAN, DAN POLA ASUH TERHADAP STUNTING PADA BALITA DENGAN DIARE SEBAGAI VARIABEL INTERVENING
}

\author{
Al Ihsan ${ }^{1)}$, Muchsin Riviwanto' ${ }^{1)}$, Darwel ${ }^{1)}$ \\ Poltekkes Kemenkes Padang
}

Koresponden : Al Ihsan

Email : al_ihsan@gmail.com

\begin{abstract}
Stunting is one of the main challenges that is currently faced by the health sector in the world and in developing countries, including Indonesia. Stunting is caused by a direct factors consisting of the amount of nutrient intake and a history of infectious diseases, and indirect factors such as availability and patterns of home consumption, inadequate parenting, and inadequate clean water and sanitation. The highest prevalence of stunting toddlers in the city of Padang based on the 2017 nutritional status monitoring report (PSG) is in the working area of Air Dingin Health Center, where Balai Gadang Village has the highest prevalence of stunting toddlers at 22.2\%. This study aims to determine the environmental factors that have a direct and indirect effect on stunting in toddlers in Balai Gadang Village. This study is an analytical research design. The subjects of the study were families with stunting toddlers and inadequate sanitation facilities with a sample of 38 families. Data collection was conducted from January to June 2019 by reviewing the annual report of Air Dingin's Health Center, observing sanitation facilities, interviewing, and laboratory tests on clean water. The statistical test that has been applied is path analysis method with multiple regression test. The results of the path analysis showed that there was a direct effect of variable diarrhea duration, E. coli levels in clean water sources, and the application of unhygienic and non-sanitary parenting to stunting. Indirect effects through diarrhea duration variables, ie E. coli levels in clean water sources and non-sanitary family toilet quality on stunting.
\end{abstract}

Keywords : Stunting; diarrhea; clean waters; latrines; parenting; toddlers

\section{Pendahuluan}

Kesehatan merupakan keadaan sehat, baik secara fisik, mental, spiritual, maupun sosial yang memungkinkan setiap orang untuk hidup produktif secara sosial dan ekonomis. Peningkatan kegiatan dalam upaya untuk memelihara dan meningkatkan derajat kesehatan masyarakat merupakan salah satu upaya dalam rangka pembentukan sumberdaya manusia Indonesia, serta peningkatan ketahanan daya saing bangsa bagi pembangunan nasional.

Pertumbuhan dan perkembangan anak adalah fase penting yang perlu dimaksimalkan dalam pencapaian derajat kesehatan di masa yang akan datang. Tumbuh kembang anak sangat dipengaruhi oleh asupan gizi yang optimal serta kondisi lingkungan yang sehat. Oleh karena itu, orang tua sangat berperan dalam memaksimalkan pencapaian pertumbuhan dan perkembangan anak dengan memperhatikan kedua faktor tersebut.

Menurut Poonum dan William (2012) Environmental Enteropathy adalah gangguan subklinis pada usus terutama usus halus yang disebabkan oleh higiene dan sanitasi lingkungan yang buruk sehingga menimbulkan kontaminasi tinja konstan di dalam lingkungan. Adanya peradangan pada usus menyebabkan lemahnya daya serap zat gizi dari makanan yang masuk ke dalam tubuh. Hal ini berdampak pada status gizi terutama pada balita yang dapat meningkatkan risiko terjadinya malnutrisi, gizi buruk, dan stunting dalam pertumbuhan balita.

Masalah stunting adalah salah satu tantangan utama yang saat ini dihadapi sektor kesehatan di Indonesia. Stunting adalah masalah kesehatan pada pertumbuhan anak sebagai akibat kekurangan gizi kronis dan faktor lingkungan lainnya. Stunting didefinisikan sebagai status gizi yang berdasarkan tinggi badan menurut usia dibawah -2 SD standar median kurva pertumbuhan anak (WHO, 2010). Stunting pada masa anak-anak berdampak pada tinggi badan yang pendek dan penurunan pendapatan saat dewasa, rendahnya angka masuk sekolah, dan penurunan berat lahir keturunannya kelak.

Stunting pada anak dapat disebabkan oleh faktor langsung, tidak langsung, dan faktor yang paling mendasar. Faktor langsung yang terdiri dari jumlah asupan gizi dan riwayat penyakit infeksi. 
Faktor tidak langsung seperti ketersediaan dan pola konsumsi rumah, pola asuh yang tidak memadai, serta air bersih dan sanitasi yang tidak memadai. Sedangkan faktor yang paling mendasar ialah status ekonomi keluarga, pendidikan, serta pembangunan ekonomi, politik, sosial, dan budaya.

Interaksi antara kekurangan gizi, penyakit infeksi, dan tumbuh kembang merupakan hal yang kompleks. Studi menunjukkan bahwa adanya hubungan timbal-balik antara status gizi anak

dengan peristiwa sakit infeksi terutama (diare dan infeksi saluran pernafasan). Menurut Pablo dalam Korpe (2012) kemudahan akses air bersih dan sanitasi merupakan hak asasi manusia sebagai dasar dalam memperoleh kesehatan tubuh. Ia menyatakan 3.5 juta orang di dunia meninggal setiap tahunnya akibat penyakit tular air dan kontaminasi tinja di lingkungan seperti diare. Menurut Subagyo dkk (2010) Diare karena infeksi terjadi disebabkan makanan yang terkontaminasi masuk melalui rute fecal-oral dan air dari sumber yang tidak terlindungi sehingga mudah tercemar. Menurut Checkly et.al. (2002) Anak-anak dengan sakit diare $1.5 \mathrm{~cm}$ lebih pendek dari anak-anak yang tidak pernah mengalami diare pada waktu 24 bulan pertama kehidupannya.

Penerapan perilaku hidup bersih dan sehat dalam pola asuh anak sangat penting untuk proses tumbuh kembangnya. Mulai dari membersihkan badan secara teratur, penerapan cuci tangan pakai sabun dan air mengalir, pengolahan air minum dan makanan yang memenuhi syarat, menggunakan air bersih, menggunakan jamban sehat, pengelolaan limbah cair yang memenuhi syarat, mengelola sampah rumah tangga dengan baik, dan sebagainya. ${ }^{10}$ Menerapkan kebiasaan mencuci tangan pakai sabun dalam pola asuh anak terbukti efektif dalam menurunkan kejadian diare yaitu sebesar 47\%. ${ }^{11}$ Menurut Spears, Ghosh, \& Cumming (2013) peningkatan 10\% dalam open defecation meningkatkan $0,7 \%$ stunting.

Secara global, pada tahun 2011 lebih dari $25,7 \%$ jumlah anak yang berumur dibawah lima tahun yaitu sekitar 165 juta anak mengalami stunting. Lebih dari $90 \%$ anak stunting di dunia berada di Afrika (36\%) dan Asia (27\%) pada tahun 2011 tetap menjadi masalah kesehatan masyarakat yang sering tidak dikenali. ${ }^{13}$ Menurut WHO, prevalensi balita pendek menjadi masalah kesehatan masyarakat jika prevalensinya $20 \%$ atau lebih pada suatu wilayah.

Riset Kesehatan Dasar tahun 2018 melaporkan Status gizi balita stunting (pendek dan sangat pendek) di Indonesia adalah 30,8\%.
Jika dibandingkan dengan jumlah balita stunting tahun $2010(35,6 \%)$ dan tahun 2013 $(37,2 \%)$ tidak menunjukan penurunan/perbaikan yang signifikan. ${ }^{16}$ Dapat disimpulkan bahwa persentase balita pendek di Indonesia masih tinggi dan merupakan masalah kesehatan yang harus ditanggulangi sebab prevalensi angka stunting yang masih tinggi (>20\%).

Ibukota Provinsi Sumatera Barat yaitu Kota padang tidak terlepas dari masalah stunting. Menurut hasil pemantauan status gizi (PSG) Dinas Kesehatan Kota Padang tahun 2017 angka kejadian stunting di Kota Padang yaitu 20,05\%atau seperlima dari jumlah balita di Kota Padang mengalami stunting. ${ }^{17}$ Hal ini tentu tidak wajar mengingat banyaknya kemudahan dalam meningkatkan status gizi balita yang ada di kota dibandingkan dengan desa seperti akses air bersih dan air minum serta akses sanitasi yang memadai, pendapatan ekonomi keluarga yang tinggi, mudahnya mendapatkan suplemen penambah gizi untuk balita, dan sebagainya.

Prevalensi balita stunting tertinggi di Kota Padang berada pada wilayah kerja Puskesmas Air Dingin Kecamatan Koto Tangah. Sebesar 21,43\% dari jumlah balita dinyatakan stunted (sangat pendek) dan 35,71\% dari jumlah balita mengalami stunting (pendek) di wilayah kerja Puskesmas Air Dingin. Kelurahan balai gadang memiliki angka prevalensi stunting yang paling tinggi dari kelurahan lainnya yang berda di wilayah kerja Puskesmas Air Dingin yaitu 22,2\%. Menurut laporan tahunan puskesmas tahun 2017 ditemukan $18 \%$ dari jumlah penduduk tidak memiliki akses air minum yang memenuhi syarat dan sebanyak $28 \%$ dari jumlah penduduk masih buang air besar sembarangan.

\section{Metode Penelitian}

Penelitian ini merupakan rancangan penelitian analitik dengan menerapkan metode path analysis. Penelitian ini dilakukan di kelurahan balai gadang. Waktu pelaksanaan penelitian ini yaitu pada bulan Januari-Juni 2019. Populasi dalam penelitian ini adalah seluruh keluarga yang memiliki anak balita stunting dan tercatat oleh petugas kesehatan di Kelurahan Balai gadang berdasarkan laporan tahunan 2018 adalah 26 balita. Teknik pengambilan sampel yang digunakan adalah purposive sampling dengan kriteria sebagai berikut: (a) Keluarga dengan balita stunting (b) Keluarga dengan fasilitas sanitasi yang tidak memadai (c) Keluarga yang menggunakan sumber air bersih berupa sumur gali. Jumlah sampel dalam penelitian ini adalah 19 keluarga yang memenuhi kriteria inklusi ditambah dengan 19 keluarga dengan balita normal dan fasilitas sanitasi yang tidak memadai, sehingga 
didapat total sampel ialah 38 Keluarga. Hal ini bertujuan untuk mengetahui tingkat signifikan pengaruh antar variabel. Pengumpulan data dilakukan dengan menggunakan lembar observasi, uji laboratorium, kuesioner dan wawancara langsung. Pengolahan data dilakukan menggunakan program pengolahan data dengan uji regresi berganda dan analisis data univariat dan bivariat.

\section{Hasil}

Tabel 3.1 Tabel Statistik Deskriptif Variabel Penelitian di Kelurahan Balai Gadang Tahun 2019

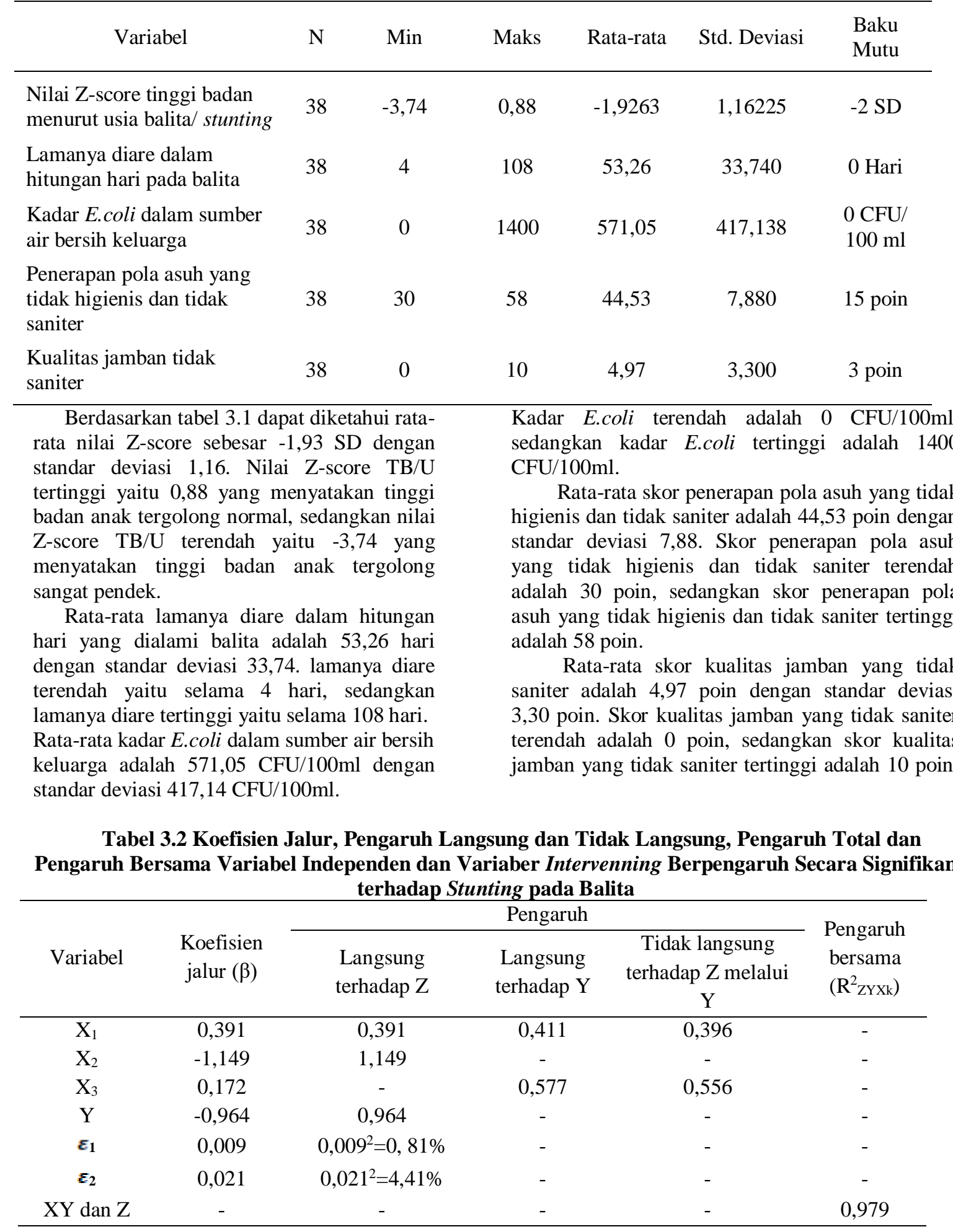


Keterangan:

$\mathrm{Z}$ : Stunting

$\mathrm{X}_{1}$ : Kadar E.coli dalam sumber air bersih

$\mathrm{X}_{2}$ : Pola asuh yang tidak higienis dan saniter

$\mathrm{X}_{3}$ : Kualitas jamban yang tidak saniter

$\mathrm{Y}$ : Lamanya diare dalam hitungan hari

$\varepsilon_{1}:$ Kontribusi variabel lain diluar analisis jalur sub struktur 1

$\varepsilon_{2}$ : Kontribusi variabel lain diluar analisis jalur sub struktur 2

Berdasarkan tabel 3.2 kadar E.coli dalam sumber air bersih berpengaruh secara simultan dan signifikan terhadap stunting dengan nilai koefisien jalur/beta sebesar $0,391(\beta=0,391)$. Serta berpengaruh secara tidak langsung melalui lamanya diare terhadap stunting dengan nilai koefisien jalur/beta sebesar 0,396 $(\beta=0,396)$.

Pola asuh yang tidak higienis dan tidak saniter berpengaruh secara simultan dan signifikan terhadap stunting pada balita dengan nilai koefisien jalur/beta sebesar 1,149 $(\beta=-1,149)$

Kualitas jamban yang tidak saniter tidak berpengaruh secara simultan dan signifikan terhadap stunting pada balita dengan nilai dengan nilai koefisien jalur/beta sebesar 0,172 $(\beta=0,172)$. Namun berpengaruh secara tidak langsung dengan nilai koefisien jalur/beta sebesar $0,556(\beta=0,556)$.

Lamanya diare berpengaruh secara simultan dan signifikan terhadap stunting pada balita dengan nilai koefisien jalur/beta sebesar $-0,964(\beta=-0,964)$.

\section{Pembahasan}

Rata-rata lamanya diare dalam hitungan hari yang dialami balita di Kelurahan Balai Gadang tergolong tinggi. Pada dasarnya setiap balita usia $0-60$ bulan sebaiknya tidak mengalami gangguan penyerapan zat gizi dalam sistem pencernaannya. Dari hasil penelitian diperoleh persamaan $Z=a+\beta_{z y} Y$ atau $Z=5,426-0,964 Y$ yang menyatakan bahwa setiap kenaikan 1 hari atau bertambah lamanya diare 1 hari, maka akan menurunkan nilai Z-score secara langsung sebesar 4,462 dari nilai rata-rata. Nilai koefisien bernilai negatif artinya terjadi hubungan negatif antara nilai Z-score dengan lamanya diare, semakin bertambah lama diare semakin berkurang nilai Z-score TB/U balita.

Rata-rata kadar E.coli dalam air sumur gali keluarga tidak memenuhi syarat kesehatan dimana kadar E.coli untuk kebutuhan higiene sanitasi adalah $0 \mathrm{CFU} / 100 \mathrm{ml}$ Tingginya ratarata kadar E.coli dalam sumur gali keluarga di Kelurahan Balai Gadang disebabkan sumur gali yang digunakan tidak terlindung dari risiko pencemaran karena sumur gali tersebut berdekatan dengan jamban/septic tank yang dimiliki (berjarak <10 meter) serta bangunan sumur yang tidak saniter. Dari hasil pengolahan data diperoleh persamaan sebagai berikut $\mathrm{Z}=\mathrm{a}$ $+\beta_{z x 1} X_{1}$ atau $Z=5,426+0,391 X_{1}$ yang menyatakan bahwa setiap peningkatan kadar E.coli $1 \mathrm{CFU} / 100 \mathrm{ml}$ maka akan meningkatkan risiko stunting secara langsung sebesar 5,817 kali. Serta persamaan analisis jalur menyatakan bahwa $Z=a+\beta_{\text {zyx } 1} X_{1}$ atau $Z=5,426+0,396 X_{1}$ yang menyatakan bahwa setiap

peningkatan kadar E.coli 1 CFU/100ml maka akan meningkatkan risiko stunting secara tidak langsung sebesar 5,822 kali.

Berdasarkan hasil observasi ditemukan bahwa orang tua tidak menerapkan dan mengajarkan anaknya tentang pentingnya cuci tangan pakai sabun pada 6 waktu penting dan tidak buang air besar sembarangan serta sebagian besar orang tua membuang tinja bayi secara sembarangan. diperoleh persamaan sebagai berikut $Z=a+\beta_{z \times 2} X_{2}$ atau $Z=5,426-1,149 X_{2}$ yang menyatakan bahwa setiap peningkatan 1 poin penerapan pola asuh yang tidak higienis dan tidak saniter maka akan menurunkan nilai Z-score secara langsung sebesar 4,277 dari nilai rata-rata.

Rata-rata penduduk menggunakan jamban yang tidak saniter. Ditemukan bahwa sebagian besar septic tank yang digunakan penduduk tidak pernah dilakukan penyedotan secara rutin serta jarak septic tank ke sumur gali yang digunakan kurang dari 10 meter. Persamaan analisis jalur menyatakan bahwa $Z=a+\beta_{z y \times 3} X_{3}$ atau $Z=5,426+0,556 X_{3}$ yang menyatakan bahwa setiap peningkatan 1 poin kualitas sanitasi jamban yang tidak saniter maka akan meningkatkan risiko stunting secara tidak langsung sebesar 5,982 kali.

\section{Kesimpulan dan Saran}

\section{A. Kesimpulan}

Kadar E.coli dalam sumber air bersih, penerapan pola asuh yang tidak higienis dan tidak saniter, dan lamanya diare dalam hitungan hari berpengaruh secara langsung terhadap stunting pada balita. Serta kadar E.coli dalam sumber air bersih dan kualitas jamban yang tidak saniter berpengaruh secara 
tidak langsung melalui lamanya diare terhadap stunting.

B. Saran

1. Bagi Masyarakat

a. Menutup dan tidak menggunakan sumur gali yang berjarak <10 meter dari septic tank karena air sumur gali terebut berisiko terkontaminasi bakteri E.coli.

b. Memperbaiki bangunan sumur gali yang dimiliki agar dapat mengisolasi air dari kontaminan penyebab penyakit dengan memberi plester/cincin 3 meter dari permukaan tanah.

c. Menerapkan pola asuh higiene dan sanitasi dalam merawat dan mendidik balita seperti: mencuci tangan pakai sabun pada 6 waktu penting, tidak buang air besar sembarangan, dan tidak membuang tinja bayi secara sembarangan.

2. Bagi Puskesmas

a.Mengoptimalkan pemantauan dan perbaikan pada kondisi sarana sanitasi dasar masyarakat seperti sumur gali dan jamban agar terlindung dari berbagai risiko pencemaran.

b.Menggelorakan atau menerapkan aksi \#BeHygienicBeHealthy di dalam kegiatan posyandu untuk meningkatkan kesadaran dan semangat masyarakat terutama ibu akan pentingnya penerapan pola asuh higiene sanitasi dalam menanggulangi stunting pada balita.

\section{Daftar Pustaka}

Menteri Hukum Dan Hak Asasi Manusia RI. 2009. Undang Undang Nomor 36 Tahun 2009 Tentang Kesehatan. Jakarta: Sekretariat Negara RI

Notoatmodjo S. 2012. Promosi Kesehatan Dan Perilaku Kesehatan. Jakarta: Rineka Cipta.

Fikawati sandra dkk. 2017. Gizi Anak Dan Remaja. Depok: PT Raja Grafindo Persada.

Poonum S. Korpe and William A. Petri. 2012. Environmental Enteropathy: Critical Implications of a Poorly Understood Condition. Trends Mol Med. 2012:328336.
United Nations Children's Fund. 1998. The State of the World' $S$. New York: Oxford University Press.

Subagyo B dkk. 2010. Diare Akut. Jakarta: Badan Penerbit IDAI.

Syahrizal. 2014. Hubungan Penanganan Sampah Dengan Kejadian Diare Pada Balita Di Wilayah Kerja Puskesmas Ingin Jaya Kabupaten Aceh Besar. 2014;9:6975.

Checkly W et. al. 2003. Effect Of Accute Diarrhea On Linear Growth In Peruvian Children. 2003;157:166-175.

Adiyanti M dan B. 2014. Pola Asuh Gizi, Sanitasi Lingkungan, dan pemanfaatan Posyandu Dengan Kejadian Stunting Pada Baduta di Indonesia (Analisis Data Riskesdas Tahun 2010).

Kementerian Kesehatan RI.2011. Pedoman Pembinaan Perilaku Hidup Bersih dan Sehat (PHBS). Jakarta: Kementerian Kesehatan; 2011:2269/MENKES/PER/XI/2011.

Kemenkes RI. 2011. Buletin Jendela Data dan Informasi Kesehatan Situasi Diare di Indonesia. J Bul Jendela Data Inf Kesehat. 2011;2:1-44.

Spears D, Ghosh A \& CO. 2013. Open Defecation and Childhood Stunting in India: An Ecological Analysis of New Data from 112 District.

Unicef WWB, Wardlaw T, Newby $\mathrm{H}$, et al. 2012. Level and Trends in Child Malnutrition.

Kementrian Kesehatan RI. 2016. Situasi balita pendek. Info Datin. 2016:2442-7659. doi:ISSN 2442-7659

Trihono dkk. 2015. Pendek (Stunting) Di Indonesia, Masalah, Dan Solusinya. Jakarta: Badan Penelitian dan Pengembangan Kesehatan.

Badan Penelitian dan Pengembangan Kesehatan. 2013. Riset Kesehatan Dasar Kementrian Kesehatan RI. Jakarta: Kementerian Kesehatan RI; 2013:50$59 ; 209$. 